\title{
TOXICIDADE DE FUNGICIDAS NO CRESCIMENTO E GERMINAÇÃO IN VITRO DO FUNGO Lasiodiplodia theobromae
}

Tamara Locatelli

Engenheira Agrônoma/ UENF

tamaralocatelli@gmail.com

Maria das Graças Machado Freire

Doutora em Biologia Funcional e Molecular/ISECENSA

freire.mgm@gmail.com

Cláudio Luiz Melo de Souza

Doutor em Produção Vegetal/UENF

claudio.melo@ig.com.br

Vicente Mussi-Dias

Doutor em Produção Vegetal/UENF

vimdias@yahoo.com.br

\section{RESUMO}

A cultura do coqueiro tem grande importância econômica e social, por ser utilizada e aplicada em muitos ramos da cadeia produtiva. Está amplamente distribuída pelo mundo, abrangendo milhões de hectares em quase 100 países. Com o aumento dos plantios, aumentam também os problemas fitossanitários, sendo o complexo de doenças, responsável por redução em cerca de $50 \%$ do potencial de produção da cultura. Recentemente tem-se voltado atenção para uma destas doenças em particular, a queima-das-folhas, causada pelo fungo Lasiodiplodia theobromae, que devido ao caráter destrutivo, de fácil disseminação e ampla gama de hospedeiros tornou-se uma ameaça à fruticultura. $\mathrm{O}$ controle de doenças do coqueiro no Brasil enfrenta problemas quanto à escassez de produtos químicos registrados, bem como sua forma prática de aplicação. Inúmeros trabalhos epidemiológicos têm sido realizados no Norte Fluminense indicando a eficiência de produtos químicos no controle da doença no campo. Assim, neste trabalho objetivou-se avaliar a sensibilidade in vitro de $L$. theobromae a quatro fungicidas sistêmicos, comumente utilizados em experimentos de epidemiologia envolvendo o complexo das doenças lixa-queima das folhas, a saber: Folicur, Tecto, Tilt e Alto 100. Avaliaram-se as concentrações 0,1; 1; 10; 100 e 1000 ppm do ingrediente ativo sobre a inibição do crescimento micelial de L. theobromae e a germinação dos conídios. Os resultados indicaram que o fungo apresenta alta sensibilidade a Folicur, Tecto e Tilt, com inibição do crescimento micelial $\left(\mathrm{ED}_{50}\right)$ menor que $1 \mathrm{ppm}$ e baixa sensibilidade ao fungicida Alto $100\left(\mathrm{ED}_{50}=50 \mathrm{ppm}\right)$. Para as análises da germinação de conídios, Folicur apresentou baixa eficiência, com concentração de inibição da germinação $\left(\mathrm{ED}_{50}\right)$ igual a $32 \mathrm{ppm}$, enquanto os fungicidas Tecto, Tilt e Alto 100 foram classificados como ineficientes, com valores de $\mathrm{ED}_{50}$ maiores que $50 \mathrm{ppm}$.

Palavras-chave: Bioensaio; Toxicidade; Proteção de plantas. 


\section{ABSTRACT}

The cultivation of coconut palmhas great economic and social importance, being used and applied in many sectors of the production chain. Is widely distributed throughout the world, covering millions of hectares in almost 100 countries. With the increase of crops, the phytosanitary problems also enhances, it is important to emphasize that the complex diseases is responsible for reduction of approximately $50 \%$ of the potential crop yield. Recently attention has turned to one of these diseases in particular, leaf blight, caused by the fungus Lasiodiplodia theobromae. This fungus has become a threat because it shows destructive character to fruit farming, easy dissemination and a very wide host range. The control of coconut palm's diseases in Brazil faces problems as the shortage of registered chemicals products, as well as its practical application form. Numerous epidemiological studies have been conducted in northern Rio de Janeiro indicating the efficiency of chemicals to control the disease in the field. Therefore, this study aimed to evaluate the in vitro susceptibility of $L$. theobromae to four systemic fungicides commonly used in experiments involving the epidemiology of the complex diseases leaf verrucosis - leaf blight, namely: Folicur, Tecto, Tilt and Alto 100. We evaluated the concentrations $0.1 ; 1 ; 10 ; 100$ and $1000 \mathrm{ppm}$ of the active ingredient for inhibiting the mycelial growth of $L$. theobromae and spore germination. The results showed that the fungus has a high sensibility to Folicur, Tecto and Tilt with inhibitory concentration of less than $1 \mathrm{ppm}$ in mycelium growth $\left(\mathrm{ED}_{50}\right)$ and low sensitivity to fungicide Alto $100\left(\mathrm{ED}_{50}=50 \mathrm{ppm}\right)$. For the conidial germination analysis, the fungicide Folicur showed low efficiency with concentration of germination inhibition $\left(\mathrm{ED}_{50}\right)$ equal to 32 $\mathrm{ppm}$. While the fungicides Tecto, Tilt and Alto 100 wererated as ineffective with $\mathrm{ED}_{50}$ values higher than 50 ppm.

Keywords: bioassay, toxicity, crop protection

\section{1- INTRODUÇÃO}

Originário do sudeste asiático, o coqueiro (Cocos nucifera L.) abrange terras intertropicais de quase 100 países com mais de 11 milhões de hectares plantados, caracterizando-se por ser uma cultura de muitas aplicações (NOEL, 2008). Apresenta grande importância econômica e social, permitindo geração de emprego e renda durante o ano todo por meio do consumo "in natura", a fabricação de produtos industrializados, como leite de coco e coco ralado, e do artesanato (FONTENELE, 2005).

No Brasil, a cultura ocupa cerca de 300.000 hectares, sendo $90 \%$ destes concentrados ao longo da faixa litorânea no Nordeste, onde predomina a variedade coqueiro gigante. No decorrer dos últimos anos, devido ao crescimento dos plantios de coqueirais da variedade anão verde, começou-se a utilizar irrigação localizada e sistemas intensivos de produção, que possibilitou distribuir os plantios em regiões não tradicionais de cultivo, como Sudeste, Centro-Oeste, Semiárido e tabuleiros costeiros no Nordeste (FONTES, et al., 2002). 
O crescimento no consumo de água de coco verde foi impulsionado por fatores como a facilidade de oferta, típica da agricultura tropical, e crescente valorização dos alimentos naturais, sendo o Rio de Janeiro grande responsável pela popularização do hábito. Juntos, o Estado do Espírito Santo e a região Norte Fluminense apresentam maior rendimento, chegando a aproximadamente 13.000 cocos/ha, quando a média no Brasil gira em torno de 7.000 cocos/há (NOEL, 2008).

Com o crescimento dos plantios comerciais de coco, começaram a aumentar os problemas fitossanitários, tais como, aqueles ocasionados por agentes etiológicos indefinidos, abióticos, insetos-pragas, aracnídeos e, principalmente, as doenças ocasionadas por fungos (FONTES e WANDERLEY, 2006).

No estado do Rio de janeiro, já foram relatadas as doenças Anel-vermelho (Bursaphelenchus cocophilus (Cobb, 1919) Baujard, 1989), declínio (Botryosphaeria rhodina (Berk. \& M.A. Curtis) Arx), fumagina (agente etiológico não citado, provavelmente Capnodium sp.), lixa-grande, lixa-pequena (Camarotella spp.), resinose (Ceratocystis paradoxa (Dade) C. Moreau), mancha-de-pestalotia (Pestalotiopsis palmarum (Cooke) Steyaert), mancha-foliar (Cercospora Fresen.), podridão-do-olho, podridão-de-sclerotium (Sclerotium Tode: Fr.), podridão-seca ("Candidatus Phytoplasma" Firrao et al. 2004), queda-dos-frutos e podridões do estipe e de raízes (Ceratocystis paradoxa (Dade) C. Moreau), podridão-basal-pós-colheita-no-fruto e queima-das-folhas (Lasiodiplodia theobromae (Pat.) Griffon \& Maubl.), dentre outras (MUSSI-DIAS, 2011), constituindo-se àquelas ocasionadas por fungos de elevada importância e de mais frequentes diagnósticos.

O fungo Lasiodiplodia theobromae é o agente causal da podridão basal pós-colheita de frutos e da queima das folhas, cujo manejo destas doenças ainda é difícil e o uso de agroquímicos é muitas vezes necessário, com ou sem associação de outras medidas de controle (FREIRE et al., 2004), e até o momento, apenas um produto químico encontra-se registrado no Ministério da Agricultura e do Abastecimento, para a doença, havendo necessidade de ensaios biológicos pautados no patossistema e bem caracterizados in vitro.

Recentemente têm sido testados produtos alternativos como o óleo de mamona e seus constituintes no controle da podridão em pós colheita (FREIRE et. al., 2013). No entanto outros trabalhos complementares são necessários para adequação e validação de produtos alternativos para aplicação prática.

Recentemente, os estudos relacionados à epidemiologia e controle da queima das folhas foram intensificados no Norte Fluminense. Caron (2012) e Monteiro et al., (2013) avaliaram a eficiência de aplicação de fungicidas nas axilas das folhas, no campo, e verificaram controle satisfatório da doença num esquema de aplicação de Ciproconazole. Posteriormente, Siqueira (2013) avaliou a eficiência desse produto em diferentes números, épocas e intervalos de aplicação, confirmando o controle do complexo queima-dasfolhas/lixa-pequena em coqueiro anão. Este último autor, avaliou ainda, em meio líquido, o efeito de 
fungicidas sobre a inibição do crescimento micelial de L. theobromae, sugerindo alta sensibilidade deste fungo a tebuconazole, thiabendazole e propiconazole.

Assim, o objetivo deste trabalho foi avaliar a sensibilidade in vitro do crescimento micelial e da germinação de conídios de L. theobromae a quatro fungicidas sistêmicos: Folicur, Tecto, Tilt e Alto 100, comumente utilizados em experimentos de epidemiologia envolvendo o complexo das doenças lixa-queima das folhas.

\section{2- MATERIAL E MÉTODOS}

Os experimentos foram conduzidos em 2012/2013, na Clínica Fitossanitária da UENF (Laboratório de Entomologia e Fitopatologia/CCTA), localizada no Campus da Universidade Estadual do Norte Fluminense Darcy Ribeiro, município de Campos dos Goytacazes, Brasil.

Foram realizados ensaios in vitro para avaliar a sensibilidade do fungo Lasiodiplodia theobromae aos fungicidas sistêmicos: Alto $100^{\circledR}$, Folicur $200^{\circledR}$, Tecto SC ${ }^{\circledR}$ e Tilt ${ }^{\circledR}$ (Tabela 1). Avaliaram-se os efeitos sobre o crescimento micelial do fungo e a germinação de conídios.

Tabela 1. Fungicidas utilizados nos bioensaios in vitro frente ao fungo Lasiodiplodia theobromae

\begin{tabular}{lcccc}
\hline \multicolumn{1}{c}{ Nome comercial } & Ingrediente ativo & Grupo químico & Tipo & CIA $^{*}$ \\
\hline Alto $100^{\circledR}$ & Ciproconazole & Triazol & Sistêmico & $100 \mathrm{~g} / \mathrm{L}$ \\
Folicur $200^{\circledR}$ & Tebuconazole & Triazol & Sistêmico & $200 \mathrm{~g} / \mathrm{L}$ \\
Tecto SC & Thiabendazole & Benzimidazol & Sistêmico & $485 \mathrm{~g} / \mathrm{L}$ \\
Tilt $^{\circledR}$ & Propiconazole & Triazol & Sistêmico & $250 \mathrm{~g} / \mathrm{L}$ \\
\hline
\end{tabular}

Concentração do ingrediente ativo

O delineamento experimental foi inteiramente casualizado (DIC) com três repetições e os dados foram submetidos à análise da variância e comparação de médias por meio do teste de Tukey $(\mathrm{P}<0,05)$ (PIMENTEL-GOMES, 2000). Para a determinação das concentrações dos fungicidas capazes de inibir 50\% do crescimento micelial ou da germinação de conídios $\left(\mathrm{ED}_{50}\right)$ foi utilizado o programa estatístico GraphPad Prism $^{\circledR}$ versão 5

\section{Isolamento do fungo e armazenamento da cultura}

O isolamento do fungo foi feito a partir de fragmentos internos de tecidos da base da raque das folhas sintomáticas e a partir de picnídios esporulados diretamente da superfície de frutos. Ambos os isolados foram mantidos em cultura pura de batata-dextrose-ágar (BDA) (DHINGRA e SINCLAIR, 1995).

Persp. online: biol. \& saúde, Campos dos Goytacazes, 17 (5), 9-22, 2015

seer.perspectivasonline.com.br 
Foram preparadas culturas monospóricas a partir de conídios em água destilada esterilizada. Esta suspensão foi semeada em placas de Petri contendo meio ágar-água e mantidas a temperatura ambiente. Após três horas, ocasião do início da germinação dos esporos, coletaram-se aqueles com tubo germinativo, transferindo-os, individualmente com auxílio de palito de dente esterilizado, para placas de Petri contendo meio BDA. Foram preparadas cerca de 10 placas contendo um esporo cada. Estas placas foram incubadas em câmara de germinação a $26^{\circ} \mathrm{C}$, dando origem às colônias monospóricas a serem utilizadas nos ensaios.

As culturas foram armazenadas em água destilada esterilizada e repicadas frequentemente para a avaliação da viabilidade dos isolados.

\section{Avaliação in vitro da sensibilidade de conídios à fungicidas sistêmicos}

Os fungicidas foram padronizados com relação à concentração do ingrediente ativo a partir das formulações comerciais (Tabela 1). Para cada fungicida foi preparada uma solução estoque de 100.000 ppm, composta pelo produto comercial e água destilada esterilizada. A partir da solução estoque procederam-se as diluições seriadas.

O delineamento experimental foi inteiramente casualizado (DIC), com cinco tratamentos, os fungicidas (Alto $100^{\circledR}$, Folicur $200^{\circledR}$, Tecto $\mathrm{SC}^{\circledR}$ e Tilt ${ }^{\circledR}$ ) e a testemunha (água). As concentrações testadas foram $0 ; 0,1 ; 1 ; 10 ; 100$ e $1.000 \mathrm{ppm}$, sendo a de 0 ppm o tratamento controle, ou seja, sem o efeito do fungicida. A partir das diluições dos fungicidas, adicionaram-se as alíquotas ao meio de cultura fundente, cujo volume final foi calculado para as concentrações desejadas.

Foi preparada suspensão de esporos a partir de cultura monospórica de $L$. theobromae por meio da lavagem da superfície da colônia com água destilada esterilizada e ajuste da concentração de esporos para $10^{6}$ conídios/mL, utilizando-se hemacitômetro de Neubauer.

Para cada placa, foram pipetadas cerca de $30 \mu \mathrm{L}$, divididos em três pontos equidistantes, $10 \mu \mathrm{L}$ cada, constituindo-se nas três repetições por tratamento. As placas foram mantidas em câmara de incubação a 26 ${ }^{\circ} \mathrm{C}$ por três horas, e posteriormente foram avaliadas sob microscópio estereoscópico de luz com objetiva de 10 x. Para tanto, em cada repetição foram contados cerca de 100 conídios, e destes, os germinados e os não germinados. Consideraram-se como conídios germinados aqueles que apresentaram tubo germinativo com comprimento no mínimo, uma vez maior que o diâmetro do esporo.

\section{Avaliação in vitro da sensibilidade micelial à fungicidas sistêmicos}

O ensaio foi realizado nas mesmas condições descritas no teste anterior com relação aos fungicidas, concentrações usadas e meio de cultura. Utilizaram-se três repetições por tratamento. 
Após a solidificação do meio de cultura nas placas, um disco de $0,8 \mathrm{~cm}$ extraído da borda da colônia monospórica foi depositado no centro de cada placa. As mesmas foram incubadas em câmara de germinação a $26^{\circ} \mathrm{C}$ e fotoperíodo de 12 horas.

A avaliação do crescimento micelial $(\mathrm{cm})$ foi realizada a cada 12 horas de incubação, medindo-se o diâmetro da colônia em dois eixos perpendiculares, passando pelo centro da colônia, até que o crescimento da mesma, no tratamento controle, atingisse a borda da placa. Essa última medida foi aquela utilizada para o cálculo da concentração inibitória.

Após o cálculo da $\mathrm{ED}_{50}$, os fungicidas foram classificados em quatro categorias de eficiência, de acordo com a fungitoxicidade, bem como a sensibilidade do fungo in vitro, de acordo com EDGINGTON et al., (1971), onde:

- $\mathrm{ED}_{50}<1$ ppm: alta fungitoxicidade e alta sensibilidade;

- $\mathrm{ED}_{50} 1$ - 10 ppm: moderada fungitoxicidade e moderada sensibilidade;

- $\mathrm{ED}_{50} 10$ - 50 ppm: baixa fungitoxicidade e baixa sensibilidade;

- $\mathrm{ED}_{50}>50$ ppm: não fungitóxico e insensível.

\section{RESULTADOS E DISCUSSÃO}

\section{Avaliação da sensibilidade de conídios}

Os conídios de L. theobromae apresentaram emissão do tubo germinativo a partir de $1 \mathrm{~h}$ após a suspensão ter sido colocada em contato com o meio de cultura. Foi estabelecido o tempo de 3 horas para interromper a germinação e efetuar a contagem daqueles que haviam germinado. Houve alta porcentagem de esporos germinados para todos os fungicidas testados na maioria das concentrações utilizadas, quando comparados com o tratamento controle (Tabela 2). A inibição da germinação ocorreu em $60 \%$ dos esporos submetidos ao fungicida Alto $100^{\circledR}$ à $1000 \mathrm{ppm}$, e em cerca de 99 e $96 \%$ sob a influência do fungicida Folicur $200^{\circledR}$, nas concentrações de 100 e 1000 ppm, respectivamente. Variações na germinação de conídios são frequentemente observadas em bioensaios de sensibilidade, como aqueles realizados por Tavares e Souza (2005) que também verificaram baixa eficiência de produtos sistêmicos na germinação de conídios de Colletotrichum gloeosporioides, entretanto, maior eficiência foi observada para o crescimento micelial do fungo.

A germinação de conídios de Myrothecium roridum foi reduzida por Tebuconazole, Ciproconazole e Propiconazole (SILVA et al., 2006), embora estes autores tivessem usado concentrações de até 100 ppm.

Persp. online: biol. \& saúde, Campos dos Goytacazes, 17 (5), 9-22, 2015

seer.perspectivasonline.com.br 
Estes dados diferem dos encontrados para esporos de L. theobromae, uma vez que somente Folicur (Tebuconazole) foi eficiente nesta concentração. 
Tabela 2. Efeito in vitro de fungicidas sistêmicos em diferentes concentrações sobre a germinação de conídios do fungo Lasiodiplodia theobromae

\begin{tabular}{|c|c|c|c|c|c|c|c|c|c|c|}
\hline \multirow{2}{*}{ Fungicida } & \multicolumn{6}{|c|}{ Concentração (ppm) } & \multirow{2}{*}{ Equação } & \multirow{2}{*}{$\mathbf{R}^{2}$} & \multirow{2}{*}{$\begin{array}{c}\text { Valor T } \\
\text { (b1) }\end{array}$} & \multirow{2}{*}{$\begin{array}{c}\text { Valor T } \\
\text { (b2) }\end{array}$} \\
\hline & $\mathbf{0}$ & $\mathbf{0 , 1}$ & 1 & 10 & 100 & 1000 & & & & \\
\hline Folicur 200 & $\begin{array}{l}100 * \mathrm{~A} \\
( \pm 0,00)\end{array}$ & $\begin{array}{l}99,33 \mathrm{~A} \\
( \pm 1,43)\end{array}$ & $\begin{array}{l}99,66 \mathrm{~A} \\
( \pm 1,43)\end{array}$ & $\begin{array}{l}98,66 \mathrm{~A} \\
( \pm 1,43)\end{array}$ & $\begin{array}{l}1,33 \mathrm{D} \\
( \pm 3,79)\end{array}$ & $\begin{array}{c}4,0 \mathrm{C} \\
( \pm 2,48)\end{array}$ & $Y=0,001000 x^{2}-1,101 x+102,25$ & $0,82 * *$ & $39,44 * *$ & $36,49 * *$ \\
\hline Tecto & $\begin{array}{c}100 \mathrm{~A} \\
( \pm 0,00)\end{array}$ & $\begin{array}{l}99,00 \mathrm{~A} \\
( \pm 2,48)\end{array}$ & $\begin{array}{l}83,00 \mathrm{~B} \\
( \pm 12,90)\end{array}$ & $\begin{array}{l}78,00 \mathrm{~B} \\
( \pm 9,93)\end{array}$ & $\begin{array}{l}81,33 \mathrm{~B} \\
( \pm 7,58)\end{array}$ & $\begin{array}{r}78,33 \mathrm{~A} \\
( \pm 16,53)\end{array}$ & $Y=0,000104 x^{2}-0,117 x+90,65$ & $0,87 * *$ & $1,75^{* *}$ & $1,60 * *$ \\
\hline Tilt & $\begin{array}{c}100 \mathrm{~A} \\
( \pm 0,00)\end{array}$ & $\begin{array}{l}99,00 \mathrm{~A} \\
( \pm 2,48)\end{array}$ & $\begin{array}{c}100 \mathrm{~A} \\
( \pm 0,00)\end{array}$ & $\begin{array}{l}99,66 \mathrm{~A} \\
( \pm 1,43)\end{array}$ & $\begin{array}{l}96,66 \mathrm{~A} \\
( \pm 1,43)\end{array}$ & $\begin{array}{r}76,66 \mathrm{~A} \\
( \pm 24,11)\end{array}$ & $Y=0,000008 x^{2}-0,031 x+99,76$ & $0,86 * *$ & $1,19 * *$ & $0,32 * *$ \\
\hline Alto 100 & $\begin{array}{l}100 \mathrm{~A} \\
( \pm 0,00)\end{array}$ & $\begin{array}{l}99,66 \mathrm{~A} \\
( \pm 1,43)\end{array}$ & $\begin{array}{l}86,66 \mathrm{~B} \\
( \pm 5,92)\end{array}$ & $\begin{array}{l}97,66 \mathrm{~A} \\
( \pm 3,79)\end{array}$ & $\begin{array}{l}70,33 \mathrm{C} \\
( \pm 1,73)\end{array}$ & $\begin{array}{c}41,0 \mathrm{~B} \\
( \pm 20,32)\end{array}$ & $Y=0,000227 x^{2}-0,283 x+96,70$ & $0,96 * *$ & $4,75^{* *}$ & $3,88 * *$ \\
\hline
\end{tabular}

* Médias ( \pm Intervalo de confiança; $\alpha=0,05)$ seguidas pelas mesmas letras na coluna não diferem entre si, segundo o Teste Tukey $(\mathrm{P} \leq 0,05 ; \mathrm{QMS}=0,643 ; \mathrm{n}=3 ; \mathrm{N}=72)$. ** Efeito de regressão significativo (Teste $\mathrm{F}, \mathrm{P} \leq 0,05$ ); ** Efeito significativo para os preditores (b1 e b2) da equação ajustada (Teste $\mathrm{t}, \mathrm{P} \leq 0,05$ ). 
Com relação à eficiência dos fungicidas e à sensibilidade dos conídios de L. theobromae aos quatro produtos testados, nenhum deles apresentou alta ou moderada eficiência/sensibilidade (Tabela 3). Folicur $200^{\circledR}$ foi o único a apresentar baixa eficiência/sensibilidade, com a mais baixa $\mathrm{ED}_{50}$. Aparentemente os esporos de $L$. theobromae, apresentam tolerância aos fungicidas testados.

Tabela 3. Eficiência de fungicidas in vitro e sensibilidade de germinação de conídios do fungo Lasiodiplodia theobromae.

\begin{tabular}{lccc}
\hline \multicolumn{1}{c}{ Fungicida } & $\mathbf{E D}_{\mathbf{5 0}}{ }^{*}(\mathbf{p p m})$ & Eficiência do fungicida** $^{* *}$ & Sensibilidade do fungo** $^{*}$ \\
\hline Alto $100^{\circledR}$ & 487 & Ineficiente & Insensível \\
\hline Folicur $200^{\circledR}$ & 32 & Baixa eficiência & Baixa sensibilidade \\
\hline Tecto SC & 3059 & Ineficiente & Insensível \\
\hline Tilt $^{\circledR}$ & 3275 & Ineficiente & Insensível
\end{tabular}

* $\mathrm{ED}_{50}=$ Concentração que inibe $50 \%$ da germinação de conídios. **Classificação em função da $\mathrm{ED}_{50}$, onde: $\mathrm{ED}_{50}<1$ ppm: alta fungitoxicidade ou alta sensibilidade; $\mathrm{ED}_{50}$ de 1 - 10 ppm: moderada fungitoxicidade ou moderada sensibilidade; $\mathrm{ED}_{50}$ de 10 - 50ppm: baixa fungitoxicidade ou baixa sensibilidade e, $\mathrm{ED}_{50}>50$ : não fungitóxico ou insensível.

\section{Avaliação da sensibilidade micelial}

Com relação ao crescimento micelial de L. theobromae, sob o efeito das diferentes concentrações de fungicidas, as bordas das placas do tratamento controle foram atingidas pelas hifas do fungo com 36 horas de semeio, ou seja, na terceira leitura. Dessa forma, embora o crescimento continuasse sendo medido a cada 12 horas para fins de análise de tempo de crescimento, definiu-se que a análise de $\mathrm{ED}_{50}$ deveria ser realizada até essa terceira avaliação.

A inibição do crescimento do fungo ocorreu com o aumento das concentrações para todos os fungicidas, sendo que a 1000 ppm não houve crescimento micelial com nenhum dos fungicidas testados (Tabela 4; Figura 1). 


\begin{tabular}{|c|c|c|c|c|c|c|c|c|c|c|}
\hline \multirow{2}{*}{ Fungicida } & \multicolumn{6}{|c|}{ Concentração (ppm) } & \multirow{2}{*}{ Equação } & \multirow{2}{*}{$\mathbf{R}^{2}$} & \multirow{2}{*}{$\begin{array}{c}\text { Valor T } \\
\text { (b1) }\end{array}$} & \multirow{2}{*}{$\begin{array}{c}\text { Valor T } \\
\text { (b2) }\end{array}$} \\
\hline & $\mathbf{0}$ & $\mathbf{0 , 1}$ & 1 & 10 & 100 & 1000 & & & & \\
\hline Folicur 200 & $\begin{array}{c}7,0 \mathrm{~A} \\
( \pm 0,00)\end{array}$ & $\begin{array}{c}5,68 \mathrm{~B} \\
( \pm 0,52)\end{array}$ & $\begin{array}{c}2,05 \mathrm{C} \\
( \pm 1,76)\end{array}$ & $\begin{array}{c}0,35 \mathrm{C} \\
( \pm 0,50)\end{array}$ & $\begin{array}{c}0,05 \mathrm{~B} \\
( \pm 0,22)\end{array}$ & $\begin{array}{c}0 \mathrm{~A} \\
( \pm 0,5)\end{array}$ & $Y=0,000043 x^{2}-0,0474 x+3,99$ & $0,96 * *$ & 2,83 & 2,63 \\
\hline Tecto & $\begin{array}{c}7,0 \mathrm{~A} \\
( \pm 0,00)\end{array}$ & $\begin{array}{l}7,0 \mathrm{~A} \\
( \pm 0)\end{array}$ & $\begin{array}{c}1,25 \mathrm{D} \\
( \pm 1,46)\end{array}$ & $\begin{array}{c}0,35 \mathrm{C} \\
( \pm 0,25)\end{array}$ & $\begin{array}{c}0,07 \mathrm{~B} \\
( \pm 0,19)\end{array}$ & $\begin{array}{c}0 \mathrm{~A} \\
( \pm 0,5)\end{array}$ & $Y=0,000045 x^{2}-0,0490 x+4,13$ & $0,88 * *$ & 2,50 & 2,32 \\
\hline Tilt & $\begin{array}{c}7,0 \mathrm{~A} \\
( \pm 0,00)\end{array}$ & $\begin{array}{c}5,13 \text { B } \\
( \pm 1,45)\end{array}$ & $\begin{array}{c}2,85 \mathrm{~B} \\
( \pm 0,87)\end{array}$ & $\begin{array}{c}1,10 \mathrm{~B} \\
( \pm 1,51)\end{array}$ & $\begin{array}{c}0,32 \mathrm{~B} \\
( \pm 0,40)\end{array}$ & $\begin{array}{c}0 \mathrm{~A} \\
( \pm 0,5)\end{array}$ & $Y=0,000042 x^{2}-0,046 x+4,22$ & $0,99 * *$ & 3,32 & 3,07 \\
\hline Alto 100 & $\begin{array}{c}7,0 \mathrm{~A} \\
( \pm 0,00)\end{array}$ & $\begin{array}{c}7,0 \mathrm{~A} \\
( \pm 0,00)\end{array}$ & $\begin{array}{c}7,0 \mathrm{~A} \\
( \pm 0,00)\end{array}$ & $\begin{array}{c}6,08 \mathrm{~A} \\
( \pm 1,01)\end{array}$ & $\begin{array}{c}1,98 \mathrm{~A} \\
( \pm 0,84)\end{array}$ & $\begin{array}{c}0 \mathrm{~A} \\
( \pm 0,5)\end{array}$ & $Y=0,000048 x^{2}-0,055 x+6,93$ & $0,91 * *$ & 29,91 & 26,53 \\
\hline
\end{tabular}

Tabela 4. Efeito in vitro de fungicidas sistêmicos em diferentes concentrações sobre o crescimento micelial (cm) do fungo Lasiodiplodia theobromae.

* Médias ( \pm Interalo de confiança; $\alpha=0,05)$ seguidas pelas mesmas letras na coluna não diferem entre si, segundo o Teste Tukey $(\mathrm{P} \leq 0,05 ; \mathrm{QMS}=0,643 ; \mathrm{n}=3 ; \mathrm{N}=72)$. ** Efeito de regressão significativo (Teste $\mathrm{F}, \mathrm{P} \leq 0,05$ ); ** Efeito significativo para os preditores (b1 e b2) da equação ajustada (Teste $\mathrm{t}$, $\mathrm{P} \leq 0,05$ ) 
Entre os quatro fungicidas testados, Alto $100^{\circledR}$ apresentou menor eficiência na inibição do crescimento micelial do fungo, surtindo efeito somente a partir de 100 ppm. Folicur $200^{\circledR}$ e Tilt ${ }^{\circledR}$ apresentaram eficiência contra o fungo a partir da concentração 10 ppm, quando comparados com a testemunha. Tecto $S C^{\circledR}$ foi o fungicida mais eficiente na concentração de 1 ppm, e a partir de 100 ppm, Folicur $200^{\circledR}$ e Tilt $^{\circledR}$ inibiram totalmente o crescimento do fungo.

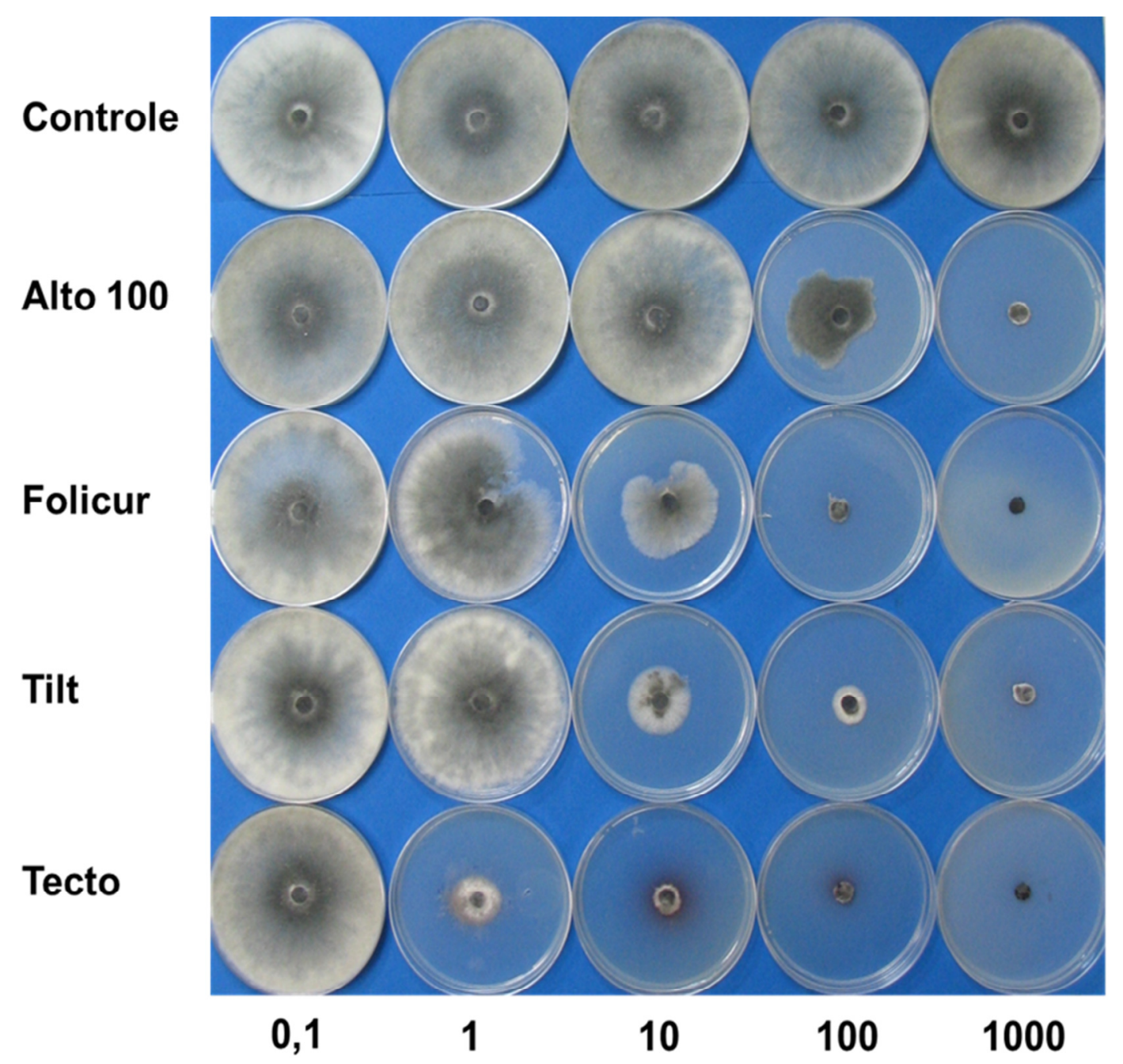

Figura 1. Avaliação do crescimento micelial do fungo Lasiodiplodia theobromae em função de diferentes concentrações (ppm) de fungicidas, após 36 horas de plaqueamento em meio de cultura.

L. theobromae apresentou alta sensibilidade a Folicur $200^{\circledR}$, Tecto $\mathrm{SC}^{\circledR}$ e Tilt ${ }^{\circledR}$, com valores de $\mathrm{ED}_{50}$ menores que 1ppm (Tabela 5). Estes fungicidas, no entanto, apresentam alta fungitoxicidade ao patógeno. $\mathrm{O}$ fungicida Alto $100^{\circledR}$ apresentou $\mathrm{ED}_{50}$ mais elevada, classificando-o como de baixa fitotoxicidade, no qual o fungo apresenta também baixa sensibilidade. 
Estes resultados são corroborados por aqueles apresentados por PEREIRA (2009) cujos estudos in vitro indicaram que Folicur $200^{\circledR}$ e Tecto $\mathrm{SC}^{\circledR}$ inibiram em $97 \%$ e $91,6 \%$, respectivamente o crescimento micelial do fungo L. theobromae.

Ao avaliar os fungicidas Tilt ${ }^{\circledR}$ e Folicur $200^{\circledR}$ quanto à eficiência dos mesmos e a sensibilidade de Colletotrichum gloesporioides, Tavares e Souza (2005), verificaram que ambos os produtos foram consistentemente eficientes para reduzir o crescimento micelial do fungo, apresentando $\mathrm{ED}_{50}<1 \mathrm{ppm}$.

Segundo SIQUEIRA (2013) L. theobromae é pouco sensível ao fungicida Alto $100^{\circledR}$, apresentando $\mathrm{ED}_{50}$ de 15,52 ppm. Nossos resultados são semelhantes aos encontrados pela autora, embora a $\mathrm{ED}_{50}$ para Alto $100^{\circledR}$ seja maior (Tabela 5). Estes dados são extremamente importantes, uma vez que há relatos de eficiência de Alto $100^{\circledR}$, no campo, na diminuição dos sintomas da queima das folhas em coqueiro (MONTEIRO et al., 2013).

Tabela 5. Eficiência de fungicidas in vitro e sensibilidade do crescimento micelial do fungo Lasiodiplodia theobromae.

\begin{tabular}{lccc}
\hline \multicolumn{1}{c}{ Fungicida } & ED $_{\mathbf{5 0}}{ }^{*}(\mathbf{p p m})$ & Eficiência do fungicida*** $^{* *}$ & Sensibilidade do fungo $^{* * *}$ \\
\hline Alto $100^{\circledR}$ & 50,05 & Baixa & Baixa \\
\hline Folicur $200^{\circledR}$ & 0,42 & Alta & Alta \\
\hline Tecto SC & Alta & Alta & Alta \\
\hline Tilt & & 0,61 & Alta
\end{tabular}

$* \mathrm{ED}_{50}=$ Concentração que inibe $50 \%$ do crescimento micelial. $* *$ Classificação em função da $\mathrm{ED}_{50}$, onde: $\mathrm{ED}_{50}<1$ ppm: alta fungitoxicidade ou alta sensibilidade; $\mathrm{ED}_{50}$ de 1 - $10 \mathrm{ppm}$ : moderada fungitoxicidade ou moderada sensibilidade; $\mathrm{ED}_{50}$ de 10 - 50ppm: baixa fungitoxicidade ou baixa sensibilidade e, $\mathrm{ED}_{50}>50$ : não fungitóxico ou insensível.

\section{CONCLUSÕES}

Todos os quatro fungicidas não foram eficientes em inibir a germinação dos esporos do fungo na maioria das concentrações testadas. No entanto, Folicur $200^{\circledR}$ apresentou melhores índices de inibição do fungo nas concentrações acima de 100 ppm. Este fungicida poderia ser indicado para testes de controle da doença no campo em fase inicial, uma vez que apresentou melhores resultados contra L. theobromae entre os produtos testados nos dois ensaios (germinação e crescimento micelial).

Os fungicidas Folicur $200^{\circledR}$, Tecto $\mathrm{SC}^{\circledR}$ e Tilt $^{\circledR}$ foram enquadrados como eficientes na inibição do crescimento micelial de L. theobromae, apresentando $\mathrm{ED}_{50}<1 \mathrm{ppm}$. Estes fungicidas poderiam ser usados em esquemas alternados de tratamento da doença, a fim de evitar o aparecimento de resistênica do patógeno. Alto $100^{\circledR}$ não foi eficiente nessa inibição, com $\mathrm{ED}_{50}=50 \mathrm{ppm}$. 


\section{REFERÊNCIAS}

CARON, E.S. Eficiência de fungicidas via aplicação axilar no controle da queima-das-folhas em coqueiro-anão verde. Campos dos Goytacazes: Universidade Estadual do Norte Fluminense Darcy Ribeiro, 2012. 105 f. Dissertação (Mestrado em Produção Vegetal) - Programa de Pós Graduação em Produção Vegetal, UENF, Campos dos Goytacazes, 2012.

DHINGRA, O.D. SINCLAIR, J.B. Basic plant pathology methods. 2 ed. Lewis Publishers: Boca Raton, 1995. 434p.

EDGINGTON, L.V.; KHEW, K.L.; BARRON, G.L. Fungitoxic spectrum of benzimidazoles compounds. Phytopathology, 61(1): 42-44, 1971.

FONTENELE, R.E.S. Cultura do coco no Brasil: caracterização do mercado atual e perspectivas futuras. In: XLIII Congresso do sober. 2005, Ribeirão Preto. Cultura do coco no Brasil. 2005. p. 1-20.

FONTES, H.R.; RIBEIRO, F.E.; FERNANDES, M.F. Coco: Produção, aspectos técnicos. Brasília: Embrapa Informação Tecnológica, 2002. p.1-9.

FONTES, H.R.; WANDERLEY, M. Situação atual e perspectivas para a cultura do coqueiro no Brasil. Aracaju: Embrapa Tabuleiros Costeiros, 2006. p. 1-16.

FREIRE, M.G.M.; SOUZA, C.L.M.; PORTAL, T.P.; MACHADO, R.M.A.; SANTOS, P.H.D.; MUSSIDIAS, V. Effect of castor bean oil on post harvest fungal pathogen of coconut: Lasiodiplodia theobromae. Journal of Plant Physiology \& Pathology, 1-2:1-7, Jul. 2013.

FREIRE, F.C.O.; VIANA, F.M.P.; CARDOSO, J.E.; SANTOS, A.A. Novos hospedeiros do fungo Lasiodiplodia theobromae no estado do Ceará. Fortaleza: Embrapa Agroindústria Tropical, 2004. p. 1-6.

MONTEIRO, C.M.; CARON, E.S.; SILVEIRA, S.F.; ALMEIDA, A.M.; SOUZA-FILHO, G.R.; SOUZA, A.L. Control of foliar diseases by the axillary application of systemic fungicides in Brazilian coconut palms. Crop Protection, 52: 78-83. 2013.

MUSSI-DIAS, V. Fitopatologia no estado do Rio de Janeiro: Histórico, índice de doenças de plantas e 15 anos de atividades da clínica fitossanitária da UENF. Campos dos Goytacazes: Universidade Estadual do Norte Fluminense Darcy Ribeiro, 2011. 283 f. Tese (Doutorado em produção vegetal) - Programa de pós graduação em produção vegetal, UENF. Campos dos Goytacazes, 2011. 
NOEL, F.L. $\quad$ Verão movido à água de coco. 2008 . 5 p. $\quad$ Disponível em: http://www.santoandre.sp.gov.br/biblioteca/bv/hemdig_txt/080324007.pdf. Acesso em 9 Nov. 2013.

PEREIRA, A.V.S. Sensibilidade a fungicidas e adaptabilidade de Lasiodiplodia theobromae patogênico ao mamão. Recife: Universidade Federal Rural de Pernambuco, 2009. 58p. Dissertação (Mestrado em Fitopatologia) - Programa de pós-graduação em Fitopatologia, Universidade Federal Rural de Pernambuco, Recife, 2009.

PIMENTEL-GOMES, F. Curso de estatística experimental. 14ª edição (Ed). Piracicaba, 2000. 477p.

SILVA, J. C.; MEYER, M. C.; COUTINHO, W. M.; SUASSUNA, N. D. Fungitoxicidade de grupos químicos sobre Myrothecium roridum in vitro e sobre a mancha-de-mirotécio em algodoeiro.Pesquisa Agropecuária Brasileira, 41(5):755-761. 2006.

SIQUEIRA, J.A.M. Eficiência da aplicação axilar de ciproconazole no controle de doenças foliares do coqueiro anão. Campos dos Goytacazes: Universidade Estadual do Norte Fluminense Darcy Ribeiro, 2013. 75 f. Dissertação (Mestrado em Produção Vegetal) - Programa de pós-graduação em produção vegetal, UENF. Campos dos Goytacazes, 2013.

TAVARES, G.M.; SOUZA, P.E. Efeito de fungicidas no controle in vitro de Colletotrichum gloeosporioides, agente etiológico da antracnose do mamoeiro (Carica papaya L.). Ciência e Agrotecnologia, 29(1): 52-59. 2005. 